\title{
Atropine exposure in adolescence predispose to adult memory loss in Wistar rats
}

\author{
A. OLAWEPO ${ }^{1 *}$, A.O. ISHOLA ${ }^{2}$, M.S. AJAO ${ }^{1}$, O.J. OLAYEMI ${ }^{1}$ and L.A. OLAYAKI ${ }^{3}$ \\ ${ }^{1}$ Department of Anatomy, University of Ilorin, P.M.B. 1515 Ilorin, Nigeria. \\ ${ }^{2}$ Department of Anatomy, Afe Babalola University, P.M.B. 5454 Ado-Ekiti, Nigeria. \\ ${ }^{3}$ Department of Physiology, University of Ilorin, P.M.B. 1515 Ilorin, Nigeria. \\ ${ }^{*}$ Corresponding author; E-mail: kunleolawepo@yahoo.co.uk; Tel: +2348035849795
}

\begin{abstract}
Some of the brain malfunctions in adulthoods have been linked to the developmental process in their childhood, especially in most adolescent who have been exposed to one form of drug abuse or another. This study investigated the effect of atropine exposure at adolescence on the memory and histology of the frontal cortex of Wistar rats and its effects on adult memory. 20 male adolescent Wistar rats were used for the study. The rats were divided into two groups of 10 rats each. The first group were administered with $100 \mathrm{mg} / \mathrm{kg}$ body weight of atropine (Atr), and the other 10 rats were given $10 \mathrm{~mL} / \mathrm{kg}$ body weight of normal saline (NS) for 7 days at adolescence. On $8^{\text {th }}$ day, the rats were subjected to novel object recognition test (NOR) and ' $\mathrm{Y}$ ' maze test to assess their memory function, 5 rats from each group were euthanized using ketamine and were perfused transcardially with $4 \%$ paraformaldehyde. Thereafter, the brains were removed and processed for histology using H\&E and Giemsa stain. The remaining 5 rats from each group were reared till adult (65 days postpartum) without treatment denoted as Atr-I and NS-I respectively. The same memory tests and histology study were conducted on the rats at adulthood. Data were analysed using Student $t$ test and $P<0.05$ was set as significant level. Atr and Atr-1showed decline in memory neither index from NOR compared with NS and NS-I respectively. Atr-I shows decline in Y maze compared to NS-I. The study concludes that atropine exposed rats show significant signs of neural cell death in the frontal cortex which progresses into adulthood as evidence from the histological findings.

(C) 2017 International Formulae Group. All rights reserved.
\end{abstract}

Keywords: Atropine, drug abuse, adolescence, adulthood, memory loss.

\section{INTRODUCTION}

Adolescence is a period of transition of physical and psychological development (Christie and Viner, 2005), and it heralded the vulnerability of stress and in some situations, opportunities to alleviate adverse effects of events experienced earlier during developmental processes (Dahl, 2004). Major activities going on in adolescent brain involved synaptic pruning (Yakovlev and
Lecours, 1967; Innocenti, 1995; Giedd et al., 1999, 2004; Winters, 2008), and prefrontal cortex (PFC) have shown to undergo some significant changes during this time (Giedd, 2004; Winters, 2008; Casey et al., 2008). Studies show that risk behaviour such as drug abuse, alcoholism, unprotected sexual intercourse with it attendant side effects peaked at adolescence. Hence, more attention and focus are on social rewards amongst them 
than the adults (Albert and Steinberg, 2011). Immaturity of the Prefrontal cortex (PFC) have also been linked with the risk seeking behaviour of adolescent (White, 2001; Chambers and Potenza, 2003; Giedd, 2004; Winters, 2008). It has also been established that PFC deal with logical reasoning and executive function especially in humans (Johnson et al., 2002).

Drug abuse among adolescent is becoming a major health problem in our environment and across the globe (Dahl, 2004; Nestler and Malenka, 2004; Winters, 2008), and this have also been attributed to progression of neurodegenerative disorders during adulthood (Nestler and Malenka, 2004). Many drugs have been used for recreation purposes among adolescent and this includes the likes of atropine (anticholinergic agent) which is commonly found in some plants like Datura metel (Griffin and Lin, 2000). Atropine, an extract from Soma plant has been shown to impair learning ability and neurogenesis (Joosen et al., 2009). Datura metel which contains tropane alkaloids induces hallucinations and metabolic disorder in rats (Abubakar et al., 2010; Damilare et al., 2010; Richard et al., 2011; Tijani et al., 2012), and have also been implicated in the disorders of hippocampal development in rats (Ishola and Adeniyi, 2013). The present study was aimed at investigating the effects of atropine exposure during adolescent on memory and its long term effects in adulthood.

\section{MATERIALS AND METHODS}

Animal care

The animals were handled carefully during the treatment using approved protocols by the Institutional Animal Care and Ethics Committee. Twenty (20) healthy male pups were obtained from the animal holding, Department of Anatomy, Faculty of Basic Medical Sciences, College of Health Sciences, University of Ilorin, Nigeria. The pups were bred till adolescent (34 days' post-parturition) before the commencement of the experiment. All the rats (pups) were housed in a standard cage, food and water was given ad libitum, and the room temperature was maintained within $22-25{ }^{\circ} \mathrm{C}$. Animal handling was in line with the ethical guidelines of the Department of Anatomy and University.

\section{Drug preparation}

Atropine (in form of eye drop) was bought from Momrota pharmacy on prescription and was used throughout the duration of the experiment.

\section{Experimental protocol}

$n=10$ rats were treated with atropine and denoted as Atr group. This was administered intra-peritoneally at a concentration of $100 \mathrm{mg} / \mathrm{kg}$ for 7 days. A separate group of $n=10$ male rats were fed on normal rat chow and treated with normal saline for 7 days denoted as NS group (Control). The remaining $n=5$ animals after initial sacrifice, each in the Atr and NS treatment groups were labelled Atr-I and NS-I representing the animals that were reared till adult after treatment. The Atr-I $(n=5)$ and NS-I $(n=5)$ categories were allowed to stay and feed freely till adulthood (64 days postpartum) with no further treatment administered.

\section{Behavioural studies}

At the end of the treatment (Atr and NS) and withdrawal phase (Atr-I and NS-I), behavioural studies were conducted using novel object recognition test (NOR) and ' $\mathrm{Y}$ ' maze test.

\section{Novel Object Recognition (NOR) Test}

The rats were subjected to novel object recognition test. A $75 \mathrm{~cm}$ x $50 \mathrm{~cm}$ x 30 $\mathrm{cm}$ transparent box was used. The rats were allowed to acclimatize to the box and the test room 3 days before the test. On the test day the rats were exposed to two identical objects to acclimatize with them for three minutes which is termed as trial 1 (T1). The rats were then put inside a cage with food and water. One hour later, that is inter-trial interval (ITI), the rats were put back inside the box with one of the object replaced by a novel one for three minutes. The time used in rearing on the old 
(old time) and new object (new time) were taken and recorded. Animal rearing was measured when the nose of the animal is less than $2 \mathrm{~cm}$ from the object while sitting on the object is not considered. The memory index was calculated using the expression:

Memory $\quad$ index $\quad(\%)$
$\frac{\text { Time spent on new object }}{\text { Total time spent on rearing both old and new object }}$
$100 \quad$ (Liet al., 2013)

\section{Y-maze test}

This is done to check the spatial working memory of the rats. A "Y" maze of $75 \mathrm{~cm} \times 25 \mathrm{~cm} \times 15 \mathrm{~cm}$ was constructed. The rats were placed facing the edge and were left to make their own decisions of the arms to follow. The durations for the test was ten minutes. The percentage alternation was measured and recorded. Visiting the three arm consecutively was termed right decision (right) and visiting one arm twice in three alternations was termed wrong decision (wrong). Percentage alternation was calculated for the rats using the expression:

$\%$ alternation $=\frac{\text { No. of right decision }}{\text { No. of total arm entry }-2} \times 100$

The place was cleaned with ethanol soaked cotton wool before placing the next animal.

\section{Animal sacrifice}

At the end of behavioural studies for Atr, NS, Atr-I and NS-I animals, animals were euthanized using ketamine. The animals were perfused transcardially with normal saline to flush out systemic blood, followed by $4 \%$ paraformaldehyde to fix the whole animal. The cranium was dissected to harvest the whole brain which was fixed in $4 \%$ paraformaldehyde. After $24 \mathrm{~h}$, the brain was sectioned in the corona plane at $2.3 \mathrm{~mm}$ anterior to the bregma to expose the frontal cortex. The tissue was processed to obtain paraffin wax embedded sections; stained routinely in haematoxylin and eosin and Giemsa stain. The images were acquired using Olympus BX 51 with Optronics CameraMagna Fire.

\section{Statistical analysis}

Data were analysed using Student $\mathrm{T}$ test using GraphPad prism V.5.0 software. The level of significant was put at $95 \%$ (i.e. $P<0.05)$. The qualitative data were shown using representative photomicrographs taken with the aid of Olympus BX 51 with Optronics Camera-MagnaFire.

\section{RESULTS}

Atropine induces non-spatial memory deficit at adolescence and adult

Atropine exposed adolescent animals showed no significant different in time spent on old and new object. Adolescent control animals (NS) showed significant increase in the time spent on new object against old object indicating memory retention (Figure 1A). Atropine exposed adolescent rats showed decline in memory index compared with the control $(P<0.05)$ (Figure 1B).Similar results were obtained from the animals that were treated at adolescent and reared till adult. The Atr-I animals show no memory retention as there is no significant different in the time spent on old and new object while NS-I showed significant different (Figure 3A). AtrI animals still show decline in memory index as compared to NS-I animals (Figure 3B).

\section{Atropine induces spatial memory deficit at adult but not adolescence}

Adolescent exposed rats and adolescent control both shows significant increase $(P<0.05)$ in the right decisions $(\mathrm{R})$ than the wrong decision (W). That is, there was retention of spatial memory in both the experimental and control group (Figure 2A). There was no significant difference in the percentage alternation of both groups (Figure 2B). There was significant difference $(P<0.05)$ in the number of right $(\mathrm{R})$ and wrong (W) decisions of Atr-I and NS-I which means retention of spatial memory (Figure 4A). However, there was significant decrease $(P<0.05)$ of percentage alternation of Atr-I animals compared to NS-I animals (Figure 4B). 


\section{Neurohistology}

Atropine exposed adolescent animals showed vacuolations and neutropils changes in the granular cell layer which were absent in the control as evident from the H\&E slide (Figure 5). Cells of atropine exposed adolescent animals were deeply stained by the Geimsa stain which are highly suggestive of nuclear fragmentation signalling apoptosis compared with the control slides in which the nuclei were not deeply stained (Figure 6). There are numerous glia cells in the atropine exposed adolescent rats compared with the controls. Frontal cortex slides of animals reared till adult showed no remarkable difference between the atropine exposed and unexposed ones (Atr-I and NS-I) as demonstrated from the H\&E stained slides (Figure 7). Giemsa stain slides shows that atropine exposed rats reared till adulthood (Atr-I) have higher number cells death compared with the normal adult controls (NSI) (Figure 8).

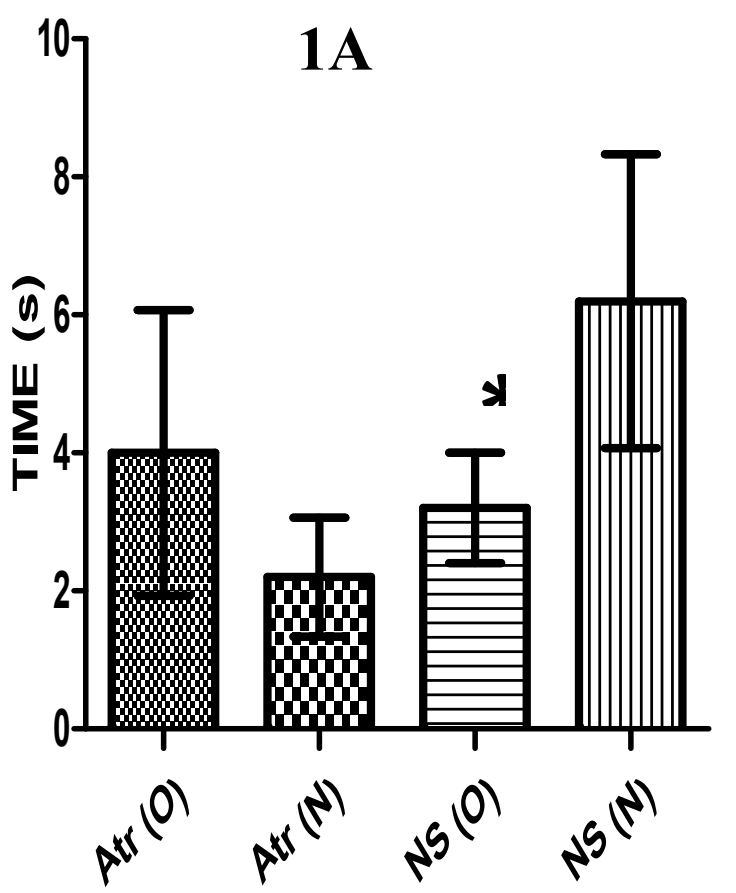

1B

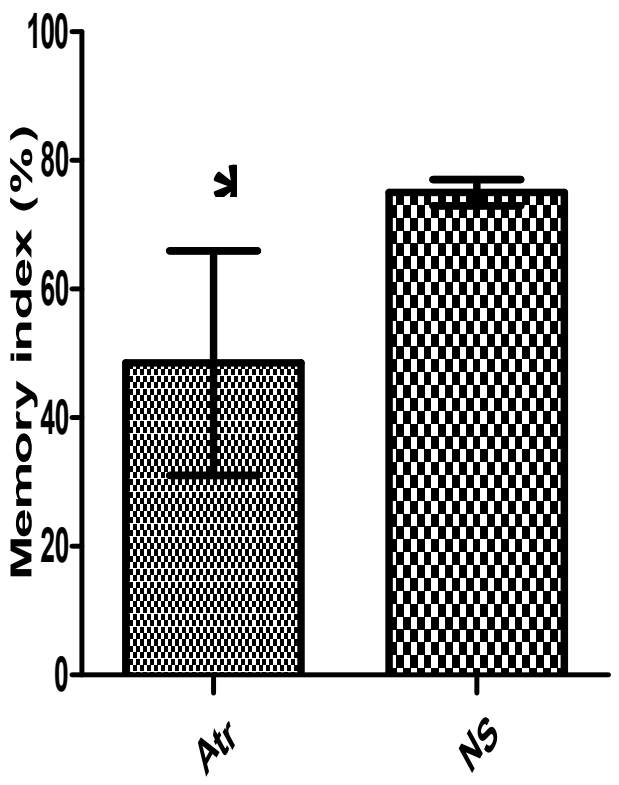

Figure 1: 1A: Comparing the time spent on old object $(\mathrm{O})$ and new object $(\mathrm{N})$ by rats that were given $100 \mathrm{mg} / \mathrm{kg}$ body weight of atropine at adolescent (Atr) and rats given $10 \mathrm{ml} / \mathrm{kg}$ body weight of normal saline at adolescent (NS) during the NOR test. 1B: Comparing the memory index between rats that were given $100 \mathrm{mg} / \mathrm{kg}$ body weight of atropine at adolescent (Atr) and rats given $10 \mathrm{ml} / \mathrm{kg}$ body weight of normal saline at adolescent (NS) during the NOR test (ITI of 1hour). The graph $1 \mathrm{~A}$ shows that there is no statistical significant in the $\mathrm{O}$ and $\mathrm{N}$ time of Atr group but there is statistical significant in the $\mathrm{O}$ and $\mathrm{N}$ time of NS $(* P<0.05)$, the graph 1B shows that there is statistical significant reduction in the memory index of Atr compared with NS $(* P<0.05)$ 

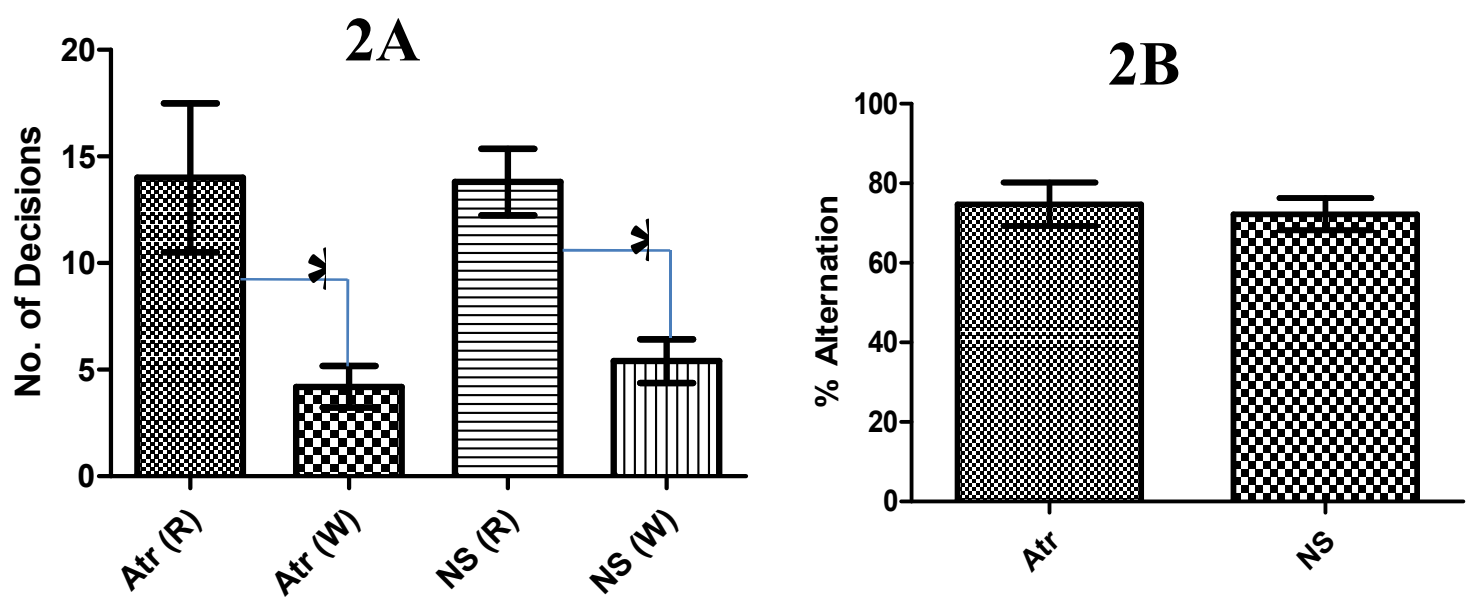

Figure 2: 2A: Comparing the number of right $(\mathrm{R})$ and wrong $(\mathrm{W})$ decisions made by the rats that were given $100 \mathrm{mg} / \mathrm{kg}$ body weight of atropine at adolescent (Atr) and rats given $10 \mathrm{ml} / \mathrm{kg}$ body weight of normal saline at adolescent (NS) during the ' $\mathrm{Y}$ ' maze test for 10 mins. $2 \mathrm{~B}$ : Comparing the percentage alternation of rats that were given $100 \mathrm{mg} / \mathrm{kg}$ body weight of atropine at adolescent (Atr) and rats given $10 \mathrm{ml} / \mathrm{kg}$ body weight of normal saline at adolescent (NS) during the ' $\mathrm{Y}$ ' maze test for 10 mins. The graph $1 \mathrm{~A}$ shows statistical significant reduction of $\mathrm{W}$ and $\mathrm{R}$ of both groups of animals; the graph $2 \mathrm{~B}$ shows no statistical significant difference in the $\%$ alternation of the groups.
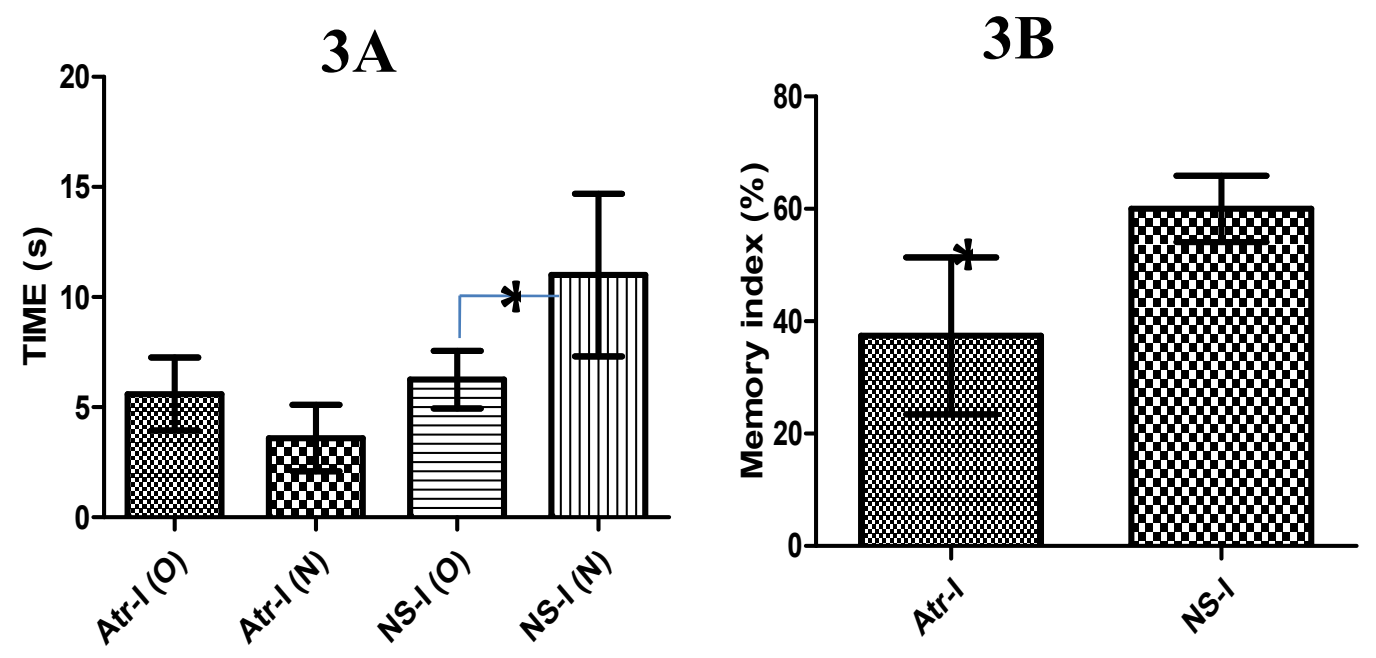

Figure3: 3A: Comparing the time spent on old object $(\mathrm{O})$ and new object $(\mathrm{N})$ by rats that were given $100 \mathrm{mg} / \mathrm{kg}$ body weight of atropine at adolescent, reared till adult (Atr-I) and rats given 10 $\mathrm{ml} / \mathrm{kg}$ body weight of normal saline at adolescent, reared till adult (NS-I) during the NOR test (ITI of 1hour). 3B: Comparing the memory index between rats that were given $100 \mathrm{mg} / \mathrm{kg}$ body weight of atropine at adolescent, reared till adult (Atr-I) and rats given $10 \mathrm{ml} / \mathrm{kg}$ body weight of normal saline at adolescent reared till adult (NS-I) during the NOR test (ITI of 1hour). The graph 3A shows statistical reduction in the time of $\mathrm{O}$ vs $\mathrm{N}$ of NS-I animals $* P<0.05$., the graph $3 \mathrm{~B}$ shows statistical reduction in the memory index of Atr-I animals than NS-I $* P<0.05$. 

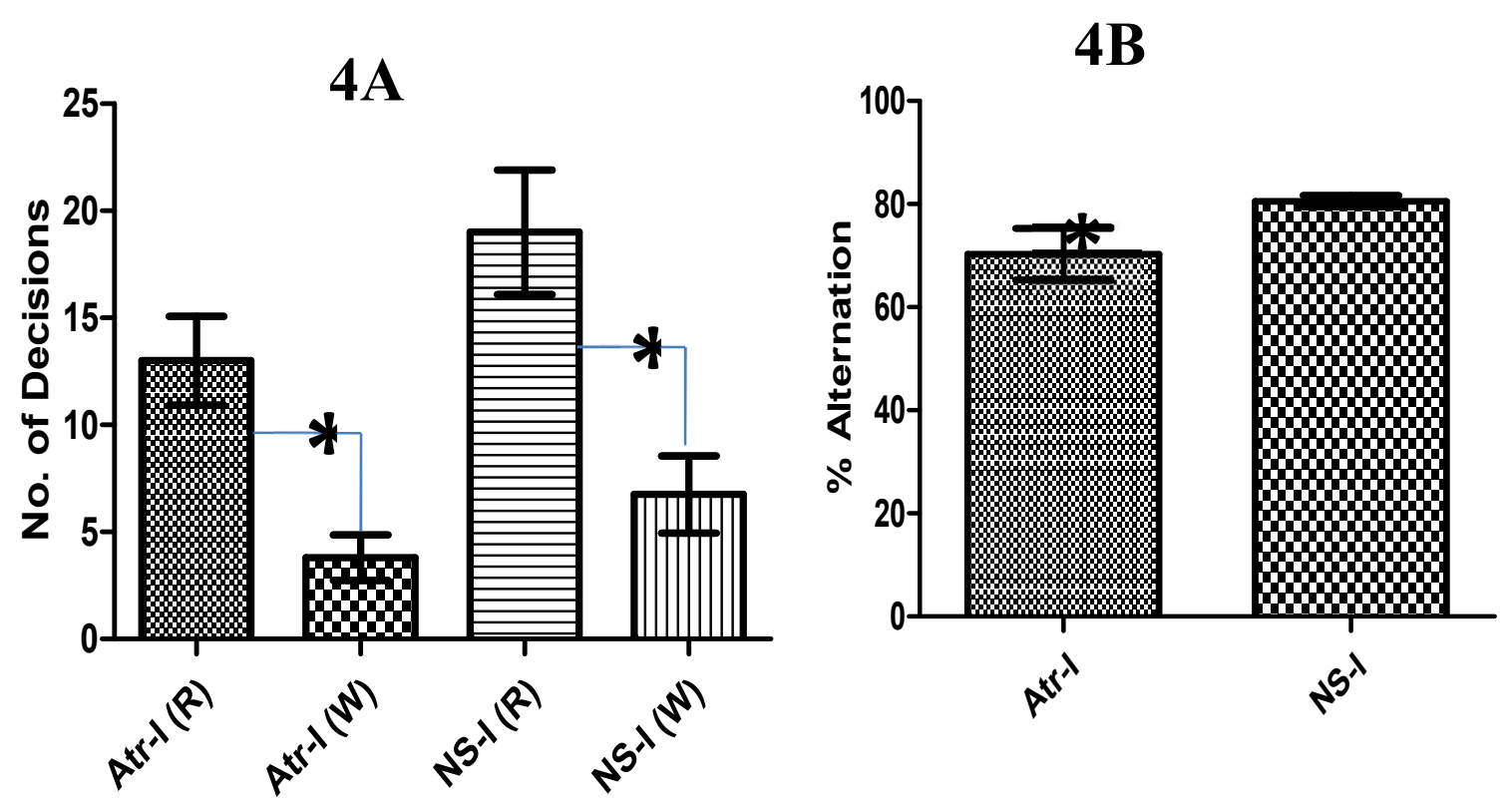

Figure:4: 4A: Comparing the No. of right $(\mathrm{R})$ and wrong $(\mathrm{W})$ decisions made by rats that were given $100 \mathrm{mg} / \mathrm{kg}$ body weight of atropine at adolescent, reared till adult (Atr-I) and rats given 10 $\mathrm{ml} / \mathrm{kg}$ body weight of normal saline at adolescent, reared till adult (NS-I) during the ' $\mathrm{Y}$ ' maze test for 10 mins. 4B: Comparing the percentage alternation of rats that were given $100 \mathrm{mg} / \mathrm{kg}$ body weight of atropine at adolescent, reared till adult (Atr-I) and rats given $10 \mathrm{ml} / \mathrm{kg}$ body weight of normal saline at adolescent, reared till adult (NS-I) during the ' $\mathrm{Y}$ ' maze test for 10 mins. The graph 4A shows statistical significant difference of $\mathrm{R}$ and $\mathrm{W}$ of both groups $(P<0.05)$; the graph $4 \mathrm{~B}$ shows statistical significant reduction of $\%$ alternation of Atr-I to NS-I $* P<0.05$.

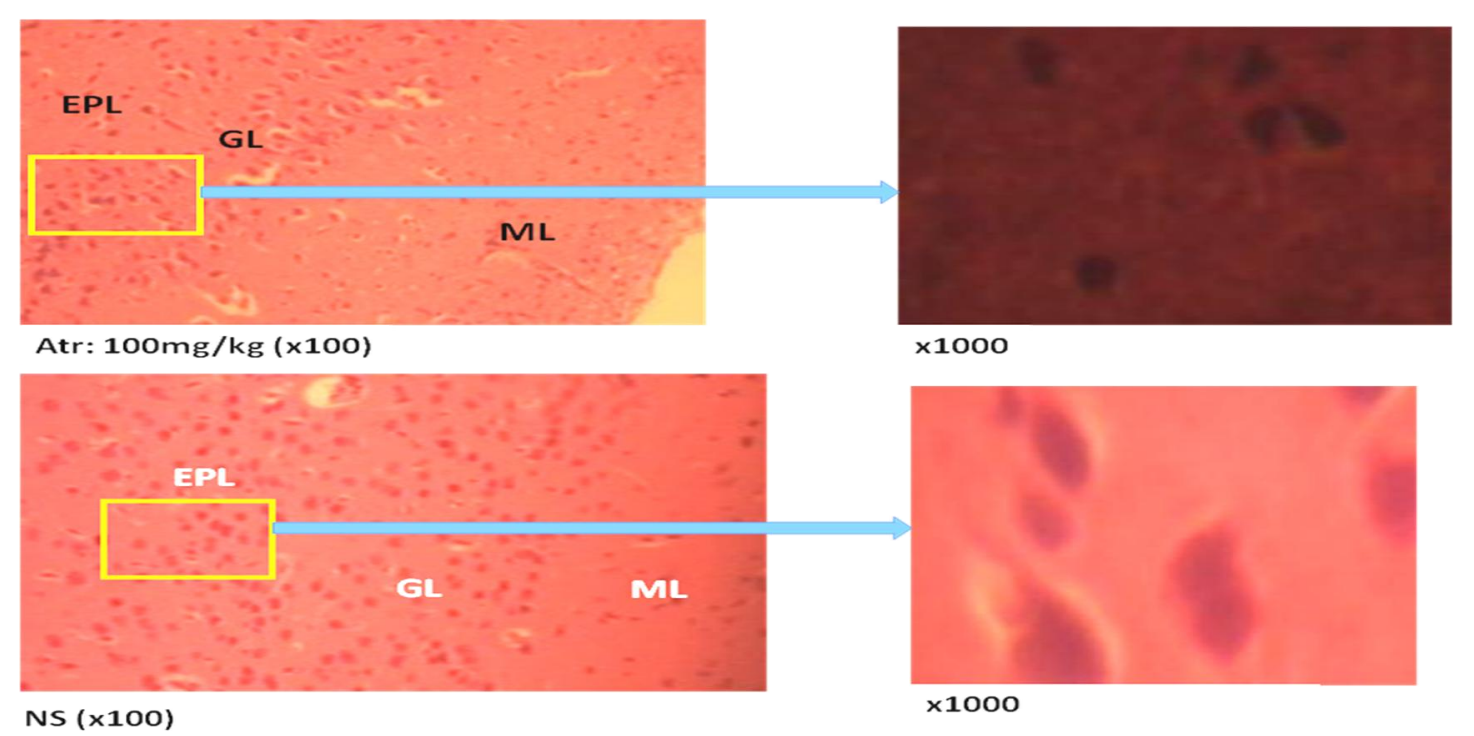

Figure 5: Photomicrograph of frontal cortex of Atr and NS. H\&E. x100, x1000. (ML- molecular layer; GL- granular layer; EPL- external pyramidal layer). Atr shows more of vacuolations than the NS group at low power view. Pyramidal cells structure has been altered at high power view (x1000) compared with the NS. 

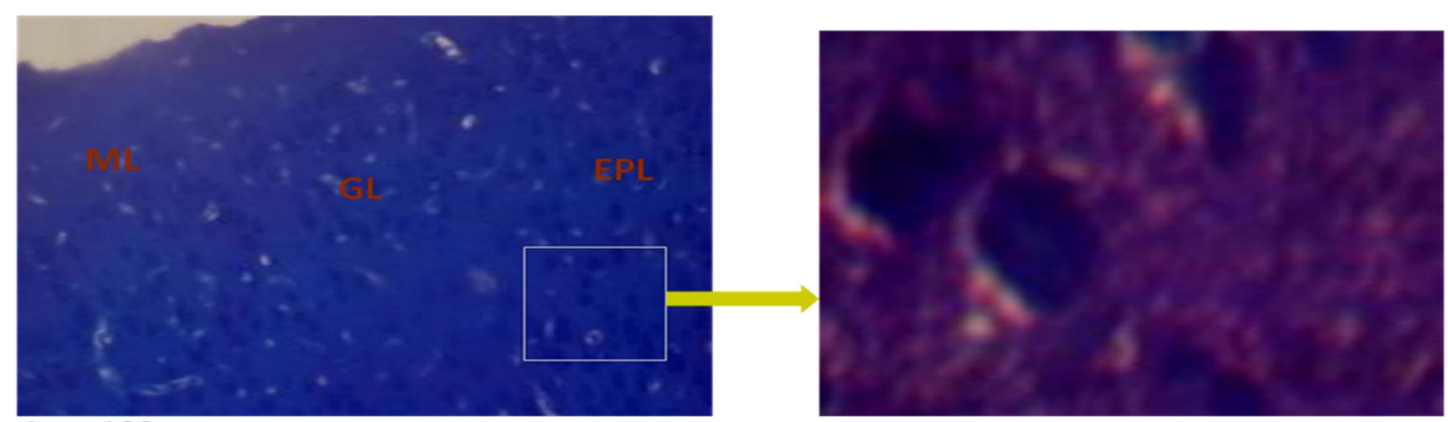

Atr. $\times 100$

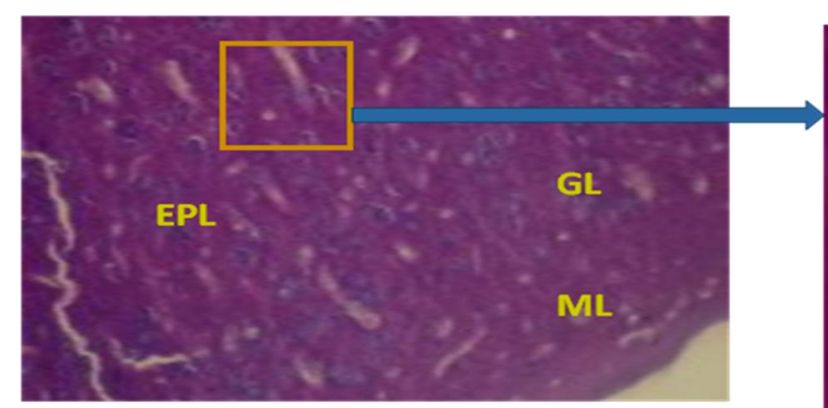

$\mathbf{x 1 0 0 0}$

NS. $\times 100$

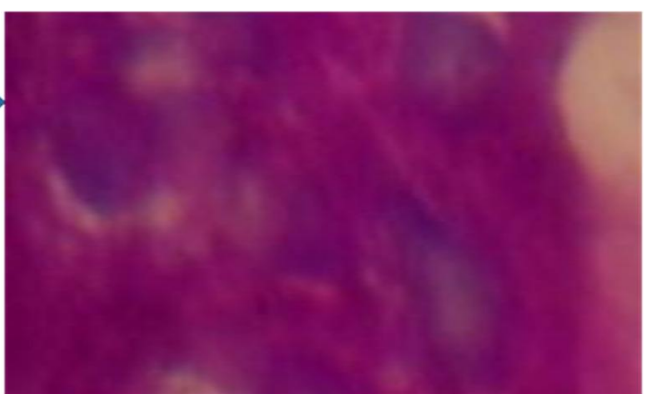

$\times 1000$

Figure 6: Photomicrograph of frontal cortex of Atr and NS rats. Geimsa stain. x100, x1000. (ML- molecular layer; GL- granular layer; EPL- external pyramidal layer). The nucleus of Atr is deeply stained by the Geimsa stain indicating nuclear fragmentation which is a pointer to apoptosis compared to NS slides which the nucleus is not deeply stained by the stain.

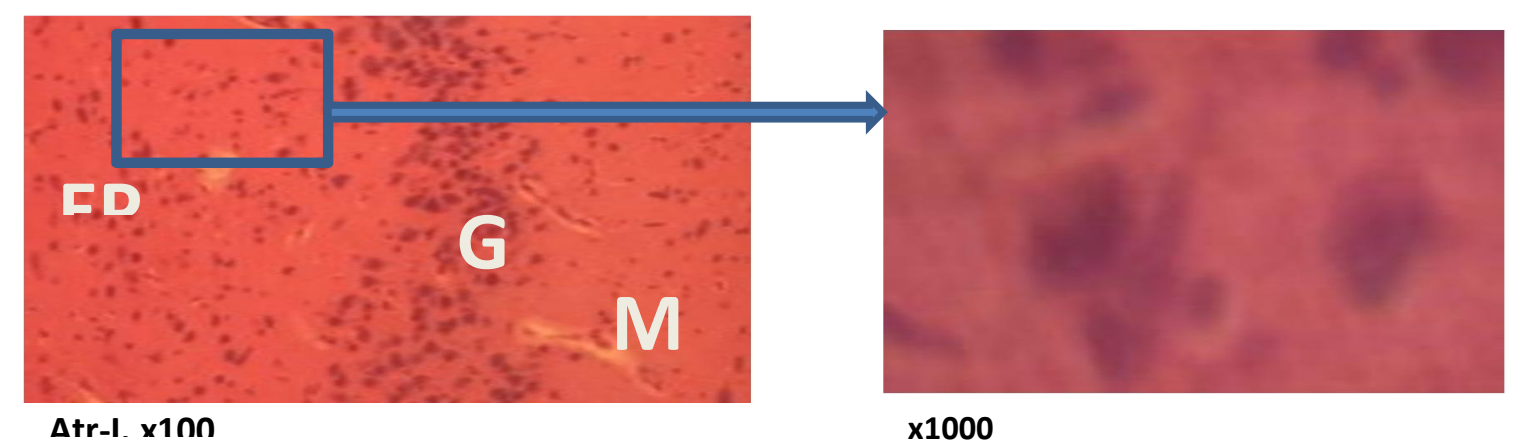

\section{Atr-I. x10n}

$\mathbf{x 1 0 0 0}$

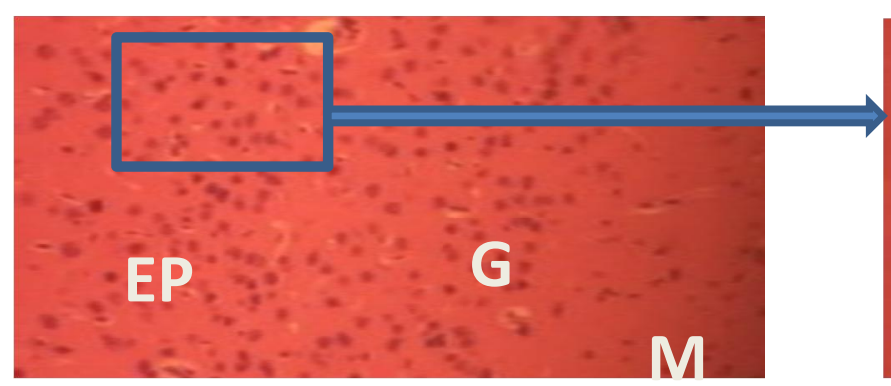

NS-I. $\mathbf{x 1 0 0}$

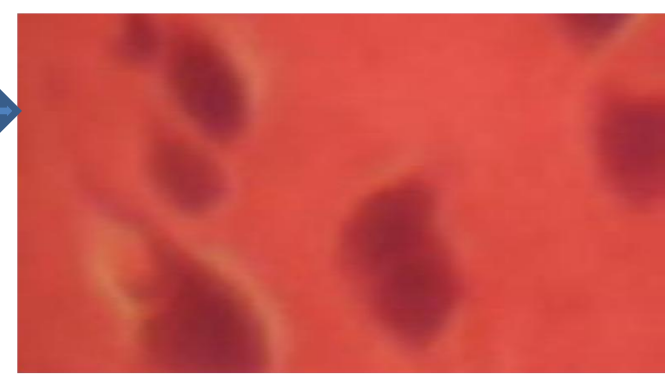

$\mathbf{x 1 0 0 0}$

Figure 7: Photomicrograph of frontal cortex of Atr-I and NS-I. H\&E stain. x100, x1000. (GL- granular layer, EPL- external pyramidal layer, ML- molecular layer). The slides show no remarkable difference from each other indicating that at adult no permanent alteration to the brain has been made. 


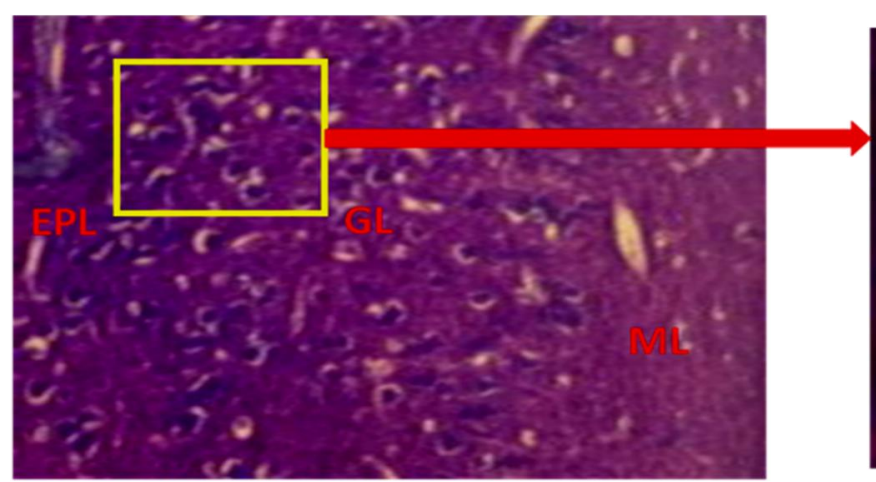

Atr-I. $\times 100$

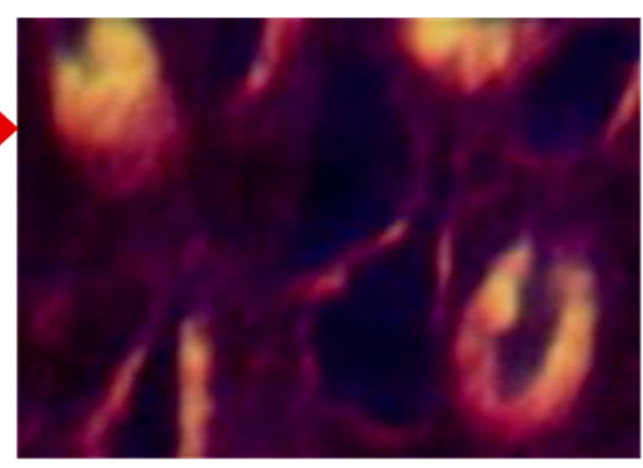

x1000

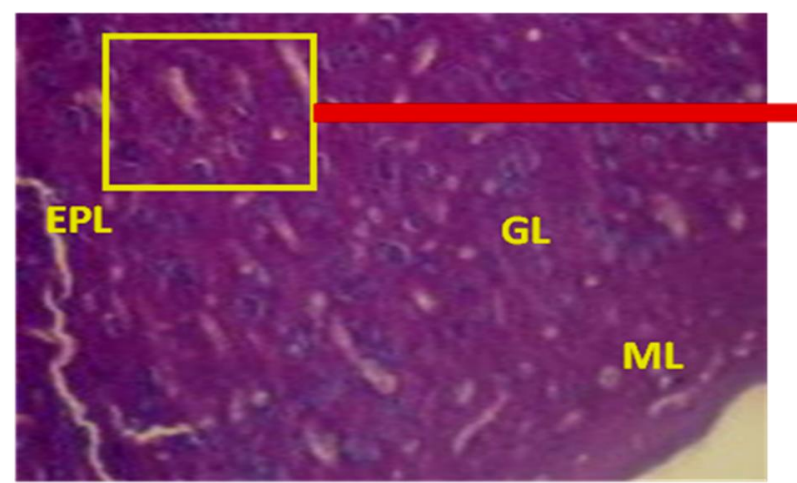

NS-I. $\times 100$

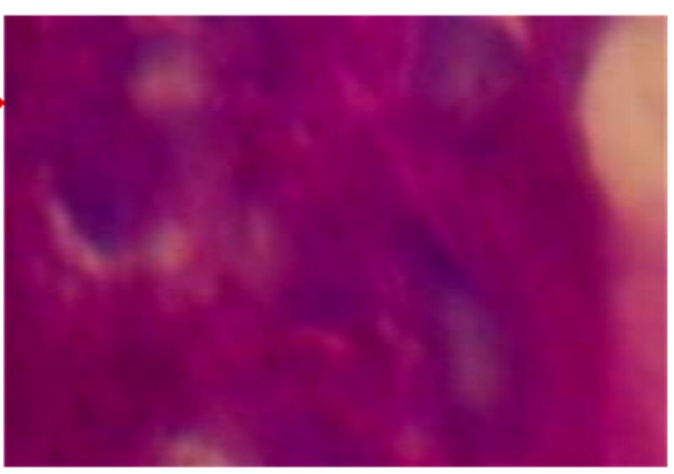

$\mathbf{x 1 0 0 0}$

Figure 8:Photomicrograph of frontal cortex of Atr-I and NS-I. Geimsa stain. x100, x1000. (GL- granular layer, EPL- external pyramidal layer, ML- molecular layer). There are no major differences in the figure, but some cell in Atr-I still stain deeply with the stain showing apoptotic cell death.

\section{DISCUSSION}

Tropane is believed to alter neurogenesis (Joels et al., 2004; Joosen, 2009), but little knowledge is known as to the mechanisms of it actions. However, it was thought to exert its activities by either involved in the destruction of the neural precursor cells thus limiting their survival rate. Atropine have been shown to have affinity for rapidly dividing cells (Chia-hua et al., 2007, 2008; Shiu et al., 2007; Li et al., 2009; Lingmei et al., 2010, 2011; Xia et. al., 2011; Xia et al., 2012), and has it is being widely used in China as herbal chemotherapy. There are claims that atropine destroys the neural precursor cells, there by altering the postnatal neurogenesis which leads to decline in memory often seen at adolescent with its attendant effects in adult life resulting in memory deficiencies and altered development of the brain. The findings of the study show that memory test conducted on adolescent rats when atropine was administered demonstrated deficit in cognition, particularly recognition memory in animals as compared with the control from the NOR result. The findings of the present study were strengthened from the earlier reports of Joels et al. (2004) and Joosen et al. (2009) that show that atropine impairs learning abilities and neurodegeneration. However, the spatial memory was not affected in the treated animal when compared with those of the control. It is an indication that spatial memory processing is different from temporal working memory. This is often reported in victims of atropine poisoning that 
are shown to still have the ability to remember places where they have been, but have anterograde amnesia following the poisoning (Henry, 1949; Holzman, 1998).

The deficit in cognition particularly recognition memory seen in the adulthood indicates that altered brain function at adolescent has a profound effect on the function of adult brain. The findings of this study was strengthened by the earlier reports of Nestle and Malenka (2004); Giedd (2004); and Winters (2008) that shows that drug abuse in adolescent enhances progression of neurodegenerative disorders at adulthood. Earlier reports show that drugs affect adult brain function when exposed during adolescence (DiazHeijtz et al., 2003, Robinson and Kolb 2004; Frost et al., 2010). Memory loss is one of early symptoms of neurodegenerative diseases (Schneider et al., 2007; Langa et al., 2004), even though, variety of disorders are caused by different drugs through different or similar pathophysiology. The observed memory loss seen in the animals reared till adult (Atr-I) following atropine administration at adolescent pose a greater risk to the development of neurodegenerative disease at adulthood. The affectation of spatial memory at the adult stage in the atropine treated group compared with the control group as seen in the ' $\mathrm{Y}$ ' maze result are clear indications of atropine long lasting effect on the brain. These observations were similar to earlier studies of drug abuse effects on spatial memories in animals (Spear 2002; Brown et al., 2000; Squeglia et al., 2009).

The histological findings from the experiment following atropine administration demonstrated neural cell death as evidenced by increase nuclear fragmentation in the frontal cortex. The present findings were strengthened by report of Rosenkranz and Wink (2008) in which the molecular pathway was identified through which various drugs of abused excite their activities. Neurohistological study of the adult frontal cortex shows that the frontal cortex shows evidences of altered cortical development. It must be noted that alteration in cortical neurogenesis predisposed to neuropsychiatry disorders later in life (Shors, 2001; Oomen et al., 2009).

\section{Conclusion}

Atropine exposure at adolescence induces cognitive deficit and neural cell death at adolescence. This also leads to adult cognitive deficit with signs of neurodegeneration. Atropine exposure at adolescent predispose to progression of neurodegenerative diseases at adulthood.

\section{COMPETING INTERESTS}

The authors declare that there are no competing interests.

\section{AUTHORS' CONTRIBUTIONS}

$\mathrm{AO}$ and AOI designed the protocol. AOI acquired and analysed data. AO, AOI, MSA, OJO and LAO executed laboratory and bench work. All were involved in preparation of the manuscript.

\section{ACKNOWLEDGEMENTS}

The authors acknowledge Adeniyi Philip for providing the behavioural test protocol.

\section{REFERENCES}

Abubakar MG, Suleiman UZ, Frank AS, Ukwani AN. 2010. Hallucinogenic effects of aqueous seeds extract of Datura metel in rats. The Internet Journal of Pharmacology, 9(1): 8143.

Albert D, Steinberg L. 2011. Judgement and decision making in adolescent. Journal of Research on Adolescent, 21(2): 211224.

Brown SA, Tapert SF, Granholm E, Delis DC. (2000) Neurocognitive functioning of adolescents: Effects of protracted alcohol use. Alcoholism: Clinical and Experimental Research, 2(42): 164-171.

Casey BJ, Getz S, Galvan A. 2008. The adolescent brain. Development Review, 28(1): $62-77$. 
Chambers RA, Potenza MN. 2003. Neurodevelopment, impulsivity, and adolescent gambling. J. Gambl Stud., 19(1): 53-84.

Chia-Hua L, Li-Yeng S, Li-Ching C, HammMing S, Eing-Mei T, Kou-Wha K. 2008. Solamargine enhances HER2 expression and increases the susceptibility of human lung cancer H661 and H69 cells to trastuzumab and epirubicin. Chem. Res. Toxicol., 21(2): 393-399.

Chia-Hua L, Li-Yeng S, Li-Ching C, HammMing S, Kou-Wha K. 2007. Solamargine upregulation of Fas, downregulation of HER2, and enhancement of cytotoxicity using epirubicin in NSCLC cells. Mol. Nutr. Food Res., 51(8): 999-1005.

Christie D, Viner R. 2005. Adolescent development. BMJ., 330(7486): 301-304

Dahl RE. 2004. Adolescent brain development: a period of vulnerabilities and opportunities. Keynote address. Ann N Y Acad Sci., 1021: 1-22.

Damilare AA, Tijani AA, Ghazal OK. 2010. Some effects of the aqueous leaf extract of Datura metel on the frontal cortex of adult Wistar rats. European Journal of Anatomy, 14(2): 83-89.

Diaz Heijtz R, Kolb B, Forssberg H. 2003. Can a therapeutic dose of amphetamine during pre-adolescence modify the pattern of synaptic organization in the brain? Eur J. Neurosci., 18: 3394-3399.

Frost DO, Page SC, Carroll C, Kolb B. 2010. Early exposure to haloperidol or olanzapine induces long-term alterations of dendritic form. Synapse, 64: 191-199.

Giedd JN, Blumenthal J, Jeffries NO, Castellanos FX, Liu H, Zijdenbos A, Rapoport JL. 1991. Brain development during childhood and adolescence: a longitudinal MRI study. Nature Neuroscience, 2(10): 861-863.

Giedd JN. 2004. Structural magnetic resonance imaging of the adolescent brain. Ann NY Acad Sci., 1021: 77-85.

Griffin WJ, Lin GD. 2000. Chemotaxonomy and geographical distribution of tropane alkaloids. Phytochemistry, 53:623-637.
Henry TA. 1949. The tropane alkaloids. In The Plant Alkaloids. Ed. Henry TA, JA Churchill Ltd: London; 69-118.

Holzman RS. 1998. The legacy of Atropos, the fate who cut the thread of life. Anaesthesiology, 89(1): 241-249.

Innocenti GM. 1995. Exuberant development of connections and its possible permissive role in cortical evolution. Trends Neurosci., 18: 397-402.

Ishola AO, Adeniyi PA. 2013. Retarded hippocampal development following prenatal exposure to ethanolic leaf extract of Datura metel leaves in Wistar rats. Nig. Med. J; 54 (6): 413-416.

Joels M, Karst H, Alfarez D, Heine VM, Qin Y, Van Riel E, Verkuyl M, Lucassen, PJ, Krugers HJ. 2004. Effects of chronic stress on structure and cell function in rat hippocampus and hypothalamus. Stress, 7: 221-231.

Johnson SC, Baxter LC, Wilder LS, Pipe JG, Heiserman JE, Prigatano GP. 2002. Neural correlates of self-reflection. Brain, 125: 1808-1814.

Joosen MJ, Jousma E, Van Den Boom TM, Kuijpers WC, Smit AB, Lucassen PJ, Van Helden HP. 2009. Long-term cognitive deficits accompanied by reduced neurogenesis after soman poisoning. Journal of Neurotoxicology, 30: $72-80$.

Langa KM, Foster NL, Larson EB. 2004. Mixed dementia: emerging concepts and therapeutic implications. JAMA, 292: 2901-2908.

Li YS, Chia HL, Li CC, Hamm MS, Eing MT, Kou WK. 2009. Solamargine induces apoptosis and enhances susceptibility to trastuzumab and epirubicin in breast cancer cells with low or high expression levels of HER2/neu. Biosci. Rep., 29(1): 35-45.

Lingmei S, Ying Z, Xia L, Huiqing Y, Aixia, C, Hongxiang, L. 2010. A lysosomalmitochondria death pathway is induced by solamargine in human K562 leukemia cells. Toxicol. In Vitro, 24(6): 15041511 . 
Nestler EJ, Malenka RC. 2004. The addicted brain. Scientific American, 290(3):78-85.

Oomen CA, Girardi CE, Cahyadi R. 2009. Opposite effects of early maternal deprivation on neurogenesis in male versus female rats. In Baune, Bernhard. PlosONE 4(1).

Richard AW, Asim T, Samuel MK, Michael, SB, John TV, Michael H, John DH. 2011. Tropane alkaloid poisoning. Medscape.

https://emedicine.medscape.com/article/ 816657-clinical

Robinson TE, Kolb B. 2004. Structural plasticity associated with exposure to drugs of abuse. Neuropharmacology, 47(1):33-46.

Rosenkranz V, Wink M. 2008. Alkaloids Induce Programmed Cell Death in Bloodstream Forms of Trypanosomes (Trypanosoma b. brucei). Journal of Molecules, 13: 2462-2473.

Schneider JA, Arvanitakis Z, Bang W, Benett, DA. 2007. Mixed brain pathologies account for most dementia cases in community-dwelling older persons. Neurology, 69: 2197-2204.

Shiu LY, Chang LC, Liang CH, Huang YS, Sheu HM, Kuo KW. 2007. Solamargine induces apoptosis and sensitizes breast cancer cells to cisplatin. Food Chem. Toxicol., 45(11): 2155-2164.

Shors TJ. 2001. Neurogenesis in the adult is involved in the formation of trace memories. Nature, 410: 372-376.

Spear LP. 2002. Alcohol's effects on adolescents. Alcohol Health and Research World, 26(4): 287-291.
Squeglia LM, Jacobus J, Tapert SF. 2009. The Influence of Substance Use on Adolescent Brain Development. Clin EEG Neurosci., 40(1): 31-38.

Tijani AA, Adekomi DA, Ibiyeye YR. 2012. Histological study of the effects of oral administration of D. metel on the visual system of male wistar rat. Scientific Journal of Biological Sciences, 1(1):11

White A. 2001. Alcohol and Adolescent Brain Development. Paper available online at http://www.duke.edu/ amwhite/alc_adol pf.html.

Winters KC. 2008. Adolescent Brain Development and Drug Abuse. Mentor Foundation Online Book.

Xia D, Fang-Shi Z, Min L, Si-Guo G. 2012. Induction of apoptosis in human hepatoma SMMC-7721 cells by solamargine from Solanumnigrum L. J. Ethnopharmacol., 139(2): 599-604

Xia L, Ying Z, Mei J, Shan-Shan L, Min C, Hong-Xiang L. 2011. Induction of actin disruption and downregulation of $\mathrm{P}$ glycoprotein expression by solamargine in multidrug-resistant $\mathrm{K} 562 / \mathrm{AO} 2$ cells. Chin. Med. J. (Engl.), 124(13): 20382044

Yakovlev PI, Lecours AR. 1967. The myelogenetic cycles of regional maturation of the brain. In Regional Development of the Brain in Early Life, Minkowski A (ed). Blackwell Scientific: Boston; 3-70. 